\title{
KETERSEDIAAN PRASARANA SANITASI DI LINGKUNGAN PERMUKIMANKUMUH (SLUM AREA) TERHADAP PENYAKIT LINGKUNGAN DI KELURAHAN BENTENGE KOTA BULUKUMBA
}

\author{
Availability of Sanitation Infrastructure in Slum Areas for Disease Based on Environment in \\ Bentenge Village, Bulukumba City \\ Setiawan Kasim ${ }^{1}$, Abdur rivai ${ }^{2}$ \\ 1,2Program Studi Sanitasi Lingkungan, Poltekkes Kemenkes Makassar \\ *)setiawankasim80@gmail.com, 082196724348
}

\begin{abstract}
Environment-based disease is a pathological condition in the form of a function or morphology of an organ caused by human interaction with everything around it that has disease potential. The availability of sanitation facilities and infrastructure is one of the causes of environmental based diseases. The presence of slums in urban areas causes the available infrastructure to meet the needs of good quality infrastructure for worship, waste, drainage, sanitation and clean water services. This study aims to determine the availability of sanitation infrastructure in slum areas for environment-based diseases in the Bentenge Village of Bulukumba City. This type of research is observational with a descriptive approach. The population in this study were all houses in the Appasarenge Environment and the Nipa City Environment in Bulukumba City as many as 280 houses. The sample in this study was 110 houses in Appasarenge and 110 in Nipa. Samples taken were 205 by using the simple random sampling method. Data analysis used Chi square test with a significance level of 0.05 (5\%). The results of the research that has been done that respondents who had the availability of clean water supply infrastructure (100\%), family latrines (100\%), sewerage (98\%), garbage disposal (97.6\%). The results of the analysis of the relationship of each independent variable with the occurrence of environmental based diseases are as follows: availability of clean water supply infrastructure $(p=0,000)$, family toilet $(p=0,000)$, sewerage $(p=1,000)$ and garbage disposal $(p=1,000)$. The conclusion is that there is a relationship between the availability of clean water supply infrastructure and family toilets to environmentbased diseases in the Bentenge Village of Bulukumba City.
\end{abstract}

Keywords; Sanitation infrastructure, slum area, environment based disease

\section{ABSTRAK}

Penyakit berbasis lingkungan adalah kondisi patologis berupa fungsi atau morfologi suatu organ tubuh yang disebabkan oleh interaksi manusia dengan segala sesuatu disekitarnya yang memiliki potensi penyakit. Ketersediaan sarana dan prasarana sanitasi merupakan salah satu penyebab terjadinya penyakit berbasis lingkungan. Hadirnya permukiman kumuh diperkotaan menyebabkan sarana prasarana yang tersedia kondisinya belum memenuhi kebutuhan sarana prasarana berkualitas baik untuk peribadatan, jaringan persampahan, drainase, sanitasi maupun tinzagkat pelayanan air bersih. Penelitian ini bertujuan untuk mengetahui ketersediaan prasarana sanitasi di lingkungan permukiman kumuh (slum area) terhadap penyakit berbasis lingkungan di Kelurahan Bentenge Kota Bulukumba. Jenis penelitian ini adalah observasional dengan pendekatan deskriptif. Populasi dalam penelitian ini adalah seluruh rumah yang berada di Lingkungan Appasarenge dan Lingkungan Nipa Kota Bulukumba sebanyak 280 rumah. Sampel dalam penelitian ini adalah jumlah rumah yang berada di Lingkungan Appasarenge sebanyak 110 rumah dan Lingkungan Nipa sebanyak 170 rumah. Sampel yang diambil sebanyak 205 dengan menggunakan metode simple random sampling. Analisa data menggunakan uji Chi square dengan taraf signifikan 0,05 (5\%). Hasil penelitian yang telah dilakukan menunjukkan bahwa responden yang memiliki ketersediaan prasarana penyediaan air bersih $(100 \%)$, jamban keluarga $(100 \%)$, saluran pembungan air limbah $(98 \%)$, pembuangan sampah (97,6\%). Hasil analisa hubungan tiap variabel bebas dengan kejadian penyakit berbasis lingkungan adalah sebagai berikut : ketersediaan prasarana penyediaan air bersih $(p=0,000)$, jamban keluarga $(p=0,000)$, saluran pembuangan air limbah $(p=1,000)$ dan pembuangan sampah $(p=1,000)$. Kesimpulannya terdapat hubungan antara ketersediaan prasarana penyediaan air bersih dan jamban keluarga terhadap penyakit berbasis lingkungan di Kelurahan Bentenge Kota Bulukumba. Kata Kunci ; Prasarana sanitasi, slum area, penyakit berbasis lingkungan

\section{Pendahuluan}

Permukiman kumuh telah menjadi isu hangat, baik di kancah nasional maupun internasional. Beberapa Negara saat ini sedang gencar-gencarnya dilakukan inovasi kebijakan perumahan yang dikhususkan bagi masyarakat berpenghasilan rendah (MBR). Terget Millenium Development Goal (MDGs) menjadi trigger bagi beberapa masyarakat tanpa terkecuali (Prayitno, 2016).

Kehadiran permukiman kumuh cenderung terus berkembang sejalan dengan laju pertumbuhan penduduk yang begitu pesat.
Bahkan, untuk memenuhi kebutuhan akan tempat tinggal, masyarakat berpenghasilan rendah hanya dapat membangun tempat tinggal pada tempat-tempat yang sesuai dengan daya dan kemampuan. Mereka menempati permukiman pada lahan yang bukan dicanangkan untuk kawasan hunian. Mereka tidak mampu membeli lahan atau rumah yang layak huni, sehingga mereka menempati lahan-lahan kosong yang memungkinkan mereka untuk mendirikan gubuk-gubuk dengan bahan bangunan murah yang terjangkau yang terbuat dari barang- 
Jurnal Sulolipu : Media Komunikasi Sivitas Akademika dan Masyarakat

Vol. 20 No.2 2020

e-issn : 2622-6960, p-issn : 0854-624X

barang bekas (sisa/buangan) seperti seng bekas, kardus, kayu-kayu potongan, bambu usang dan sebagainya pada lokasi-lokasi yang kosong dan tak bertuan di berbagai pojok kota, tanpa memperhatikan aturan-aturan kota.

Kelurahan Bentenge merupakan salah satu kelurahan yang terletak di Kecamatan Ujungbulu, Kabupaten Bulukumba. Berdasarkan SK Bupati, Kelurahan Bentenge memiliki dua kawasan kumuh yang terletak di Lingkungan Appasarenge dan Lingkungan Nipa. Luas kawasan kumuh di Kelurahan Bentenge yaitu $4 \mathrm{Ha}$, sedangkan luas yang tidak memiliki kawasan kumuh yaitu $397 \mathrm{Ha}$ (Data Kelurahan , 2019)

Menurut H.L. Blum, dalam Soekidjo (2007), derajat kesehatan dipengaruhi 4 (empat) macam faktor yaitu lingkungan, perilaku, pelayanan kesehatan, dan hereditas. Keempat faktor diatas sangat berkaitan dan saling mempengaruhi. Faktor lingkungan dan perilaku merupakan faktor terbesar yang berpengaruh terhadap tinggi rendahnya derajat kesehatan masyarakat. Hal ini dapat dilihat dari banyaknya penyakit berbasis perilaku dan gaya hidup.

Kondisi sarana sanitasi dasar perumahan dan permukiman tentu tidak tersedia pada lokasi tersebut dan apabila tersedia tentu sangat minim dan belum memadai, sehingga tidak jarang kondisi yang demikian turut menciptakan kekumuhan bagi lingkungan yang ditempatinya (Slum area). Kelurahan Bentenge merupakan salah satu wilayah yang termasuk ke dalam wilayah/ permukiman kumuh dari beberapa Kelurahan yang ada di kabupaten Bulukumba. Serta penyakit yang tertinggi wilayah tersebut yang menjadi 10 penyakit tertinggi yaitu penyakit diare, demam, dll.

Berdasarkan data Puskesmas Kota Bulukumba, angka penyakit tertinggi di Kota Bulukumba khususnya di Kelurahan Bentenge yaitu penyakit diare. Penyakit diare termasuk kedalam 5 penyakit tertinggi selama 3 tahun terakhir yakni 10,01\%. Pada tahun 2017 penderita penyakit diare sebanyak 79 orang sedangkan pda tahun 2018 sebanyak 60 orang. Kondisi prasarana sanitasi dapat mempengaruhi tingginya kejadian angka penyakit di daerah tersebut.

Tujuan dari penelitian ini adalah untuk mengetahui ketersediaan prasarana sanitasi di lingkungan permukiman kumuh (Slum area) terhadap penyakit berbasis lingkungan di kelurahan Bentenge Kota Bulukumba.

\section{Metode}

Lokasi Penelitian:

Adapun lokasi dalam penelitian ini yaitu dilaksanakan di Kelurahan Bentenge Kecamatan Ujungbulu Kota Bulukumba.

\section{Waktu Penelitian}

Adapun waktu penelitian dibagi menjadi dua tahap yaitu:

1. Tahap persiapan yaitu dengan observasi pendahuluan atau observasi lapangan atau pengambilan data data pada bulan (November) 2019.

2. Tahap pelaksanaan yaitu kegiatan penelitian yang dilaksanakan pada bulan Maret-April 2020

\section{Desain dan Variabel Penelitian}

\section{Desain Penelitian}

Desain/jenis penelitian yang digunakan dalam penelitian ini adalah observasional dengan pendekatan deskriptif atau survey langsung ke lapangan.

\section{Variabel Penelitian}

Variabel yang akan diteliti adalah variabel yang terdapat dalam ruang lingkup penelitian yang dibagi atas variable bebas, variabel terikat.

a. Variabel bebas, dalam hal ini penyakit berbasis lingkungan yang meliputi, penyediaan air bersih, saluran pembuangan air limbah, jamban keluarga dan pembuangan sampah.

b. Variabel terikat dalam hal ini yaitu penyakit berbasis lingkungan.

\section{Populasi dan Sampel}

\section{Populasi}

Populasi dalam penelitian ini adalah seluruh rumah yang berada di Lingkungan Appasarenge dan Lingkungan Nipa Kota Bulukumba sebanyak 280 rumah.

\section{Sampel}

Sampel dalam penelitian ini adalah jumlah rumah yang berada di Lingkungan Appasarenge sebanyak 110 rumah dan Lingkungan Nipa sebanyak 170 rumah. Penentuan ukuran sampel di tentukan dengan menggunakan rumus Slovins sehingga didapatkan jumlah sampel untuk 
Jurnal Sulolipu : Media Komunikasi Sivitas Akademika dan Masyarakat

Vol. 20 No.2 2020

e-issn : 2622-6960, p-issn : 0854-624X

lingkungan Appasarenge yaitu sebanyak 86 rumah sedangkan lingkungan Nipa yaitu sebanyak 119 rumah.

\section{Pengumpulan data}

1. Data Primer

Data primer diperoleh dari observasi langsung. Hasil observasi diperoleh dari kegiatan wawancara, kuesioner serta hasil pengamatan yang dilakukan di Lingkungan Appasarenge dan Lingkungan Nipa Kelurahan Bentenge Kecamatan Ujungbulu Kota Bulukumba

2. Data Sekunder

a. Data statistik diambil dari instansi pemerintahan yang ada

b. Data kajian pustaka diperoleh dari tulisan-tulisan terkait dengan materi permukiman kumuh.

\section{Analisa Data}

\section{Analisis Deskriptif}

Analisis ini dilakukan terhadap setiap variabel dari hasil penelitian ini untuk melihat distribusi frekuensi dari persentase yaitu meliputi observasi ketersediaan prasarana air bersih, jamban keluarga, saluran pembuangan air limbah dan pembuangan sampah terhadap penyakit berbasis lingkungan di Kelurahan Bentenge Kota Bulukumba.

\section{Analisis Bivariat}

Analisis data yang diguakan dalam penelitian yaitu menggunakan uji statistik yakni uji Chi-Square guna mengetahui pengaruh ketersediaan prasarana air bersih, jamban keluarga, saluran pembuangan air limbah dan pembuangan sampah terhadap penyakit berbasis lingkungan, dimana taraf signifikan $\alpha=0,05$

\section{Hasil dan Pembahasan}

Berdasarkan hasil penelitian yang telah dilakukan melalui kegiatan observasi atau pengamatan serta pengisian kuesioner secara langsung terhadap responden yang berada di Lingkungan Nipa dan Lingkungan Appasarenge yang dilakukan pada bulan Maret - April 2020 dengan jumlah sampel yang diteliti yaitu untuk Lingkungan Nipa sebanyak 119 rumah sedangkan Lingkungan Appasarenge sebanyak 86 rumah. Untuk mengetahui adanya penyakit berbasis lingkungan di kawasan tersebut dengan melihat ketersediaan prasarana sanitasi yang tersedia diantaranya: penyediaan air bersih, jamban keluarga, saluran pembuangan air limbah dan pembuangan sampah. Dari hasil data yang telah diperoleh kemudian disajikan dalam bentuk tabel dan narasi sebagai berikut:

\section{a. Penyediaan Air Bersih}

Tabel 1

\section{Hubungan Ketersediaan prasarana Sanitasi \\ Penyediaan Air BersihTerhadap Penyakit \\ Berbasis Lingkungan di Lingkungan Nipa dan \\ Lingkungan Appasarenge Kelurahan Bentenge Kota Bulukumba Tahun 2020}

\begin{tabular}{|c|c|c|c|c|}
\hline \multirow{2}{*}{$\begin{array}{c}\text { Ketersediaa } \\
\text { n Prasarana } \\
\text { Sanitasi } \\
\text { Penyediaan } \\
\text { Air Bersih }\end{array}$} & \multicolumn{2}{|c|}{$\begin{array}{c}\text { Penyakit } \\
\text { Berbasis } \\
\text { Lingkungan }\end{array}$} & \multirow[t]{2}{*}{$\begin{array}{c}\text { Tota } \\
\text { I }\end{array}$} & \multirow[t]{2}{*}{$\begin{array}{c}\text { Persentas } \\
\mathbf{e} \\
(\%) \\
\end{array}$} \\
\hline & $\begin{array}{c}\text { Tidak } \\
\text { Terken } \\
\text { a PBL }\end{array}$ & $\begin{array}{l}\text { Terken } \\
\text { a PBL }\end{array}$ & & \\
\hline Tersedia & 197 & 8 & 205 & 100 \\
\hline $\begin{array}{c}\text { Tidak } \\
\text { Tersedia }\end{array}$ & 0 & 0 & 0 & 0 \\
\hline Total & 197 & 8 & 205 & 100 \\
\hline
\end{tabular}
mengetahui hubungan ketersediaan prasarana sanitasi penyediaan air bersih terhadap penyakit berbasis lingkungan di Lingkungan Nipa dan Lingkungan Appasarenge Kelurahan Bentenge Kota Bulukumba diperoleh hasil dari 205 sampel yang diteliti, yang memiliki ketersediaan prasarana sanitasi penyediaan air bersih serta tidak terkena penyakit berbasis lingkungan sebanyak 197 rumah $(96,1 \%)$ dan yang memiliki ketersediaan prasarana sanitasi penyediaan air bersih serta terkena penyakit berbasis lingkungan sebanyak 8 rumah $(3,9 \%)$.

Hasil penelitian ini sejalan dengan sejalan dengan penelitian Langit (2016) menunjukkan bahwa ada hubungan antara penyediaan air bersih dengan kejadian penyakit berbasis lingkungan (diare) di wilayah kerja Puskesmas Rembang 2 dengan nilai $p=0,001<\alpha(0,05)$.

Masyarakat di Kelurahan Bentenge terutama di Lingkungan adalah Nipa dan Appasarenge menggunakan air PDAM sebagai sarana air bersih, selain itu juga menggunakan sumur gali sebagai air bersih. Permasalahan yang dijumpai kondisi dari konstruksi bangunan sumur yang digunakan oleh masyarakat tersebut masih belum memenuhi persyaratan yang telah ditetapkan. 
Jurnal Sulolipu : Media Komunikasi Sivitas Akademika dan Masyarakat

Vol. 20 No.2 2020

e-issn : 2622-6960, p-issn : 0854-624X

Sumur yang telah digunakan cukup lama dan volume air yang diambil relatif banyak, menyebabkan aliran tanah di sekitar sumur semakin mantap dan mendominasi. Hal ini memberi peluang lebih besar terhadap merembesnya bakteri coliform dari sumber pencemar ke dalam sumur. Sumur yang digunakan dalam waktu yang relatif lama lebih besar kemungkinan mengalami pencemaran, karena selain bertambahnya sumber pencemar juga lebih mudahnya sumber pencemar merembesnya ke dalam sumur mengikuti aliran air tanah yang berbentuk memusat ke arah sumur.

Makin banyak jumlah pemakai sumber air, berarti semakin banyak air diambil dari sumur yang berarti berpengaruh juga terhadap merembesnya bakteri coliform ke dalam sumur. Banyaknya jumlah pemaka sumur juga mempengaruhi kemungkinanterjadinya pencemaran sumur secara kontak langsung antara sumber pencemar dengan air sumur, misalnya melalui ember atau tali timba yang digunakan

Kebiasaan masyarakat membuat sumur tanpa bibir, bibir sumur tidak ditutup, mandi dan mencuci di pinggir sumur sumur akan menyebabkan air bekas mandi dan cuci sebagian mengalir kembali ke dalam sumur dan menyebabkan pencemaran. Selain itu kebiasaan membuang kotoran manusia juga ikut mempengaruhi.

\section{b. Jamban Keluarga}

\section{Tabel 2}

Hubungan Ketersediaan prasarana Sanitasi Jamban Keluarga Terhadap Penyakit

Berbasis Lingkungan di Lingkungan Nipa dan Lingkungan Appasarenge Kelurahan

Bentenge Kota Bulukumba Tahun 2020

\begin{tabular}{|c|c|c|c|c|}
\hline \multirow{2}{*}{$\begin{array}{l}\text { Ketersedia } \\
\text { an } \\
\text { Prasarana } \\
\text { Sanitasi } \\
\text { Jamban } \\
\text { Keluarga }\end{array}$} & \multicolumn{2}{|c|}{$\begin{array}{l}\text { Penyakit Berbasis } \\
\text { Lingkungan }\end{array}$} & Total & $\begin{array}{l}\text { Persenta } \\
\text { se } \\
\text { (\%) }\end{array}$ \\
\hline & $\begin{array}{l}\text { Tidak } \\
\text { Terken } \\
\text { a PBL }\end{array}$ & $\begin{array}{l}\text { Terken } \\
\text { a PBL }\end{array}$ & & \\
\hline Tersedia & 197 & 8 & 205 & 100 \\
\hline $\begin{array}{l}\text { Tidak } \\
\text { Tersedia }\end{array}$ & 0 & 0 & 0 & 0 \\
\hline Total & 197 & 8 & 205 & 100 \\
\hline
\end{tabular}

Berdasarkan Crosstabulation untuk mengetahui hubungan ketersediaan prasarana sanitasi jamban terhadap penyakit berbasis lingkungan di Lingkungan Nipa dan Lingkungan Appasarenge Kelurahan Bentenge Kota Bulukumba diperoleh hasil dari 205 sampel yang diteliti, yang memiliki ketersediaan prasarana sanitasi jamban serta tidak terkena penyakit berbasis lingkungan sebanyak 197 rumah $(96,1 \%)$ dan yang memiliki ketersediaan prasarana sanitasi jamban serta terkena penyakit berbasis lingkungan sebanyak 8 rumah (3,9\%).

Berdasarkan hasil observasi dan wawancara terhadap responden di Lingkungan Nipa dan Lingkungan Appasarenge Kelurahan Bentenge Kota Bulukumba jenis jamban yang digunakan oleh masyarakat setempat ialah jamban leher angsa, baik dilengkapi dengan penampungan maupun dengan tangki septik

sebanyak $100 \%$. Artinya semua masyarakat sebagai responden, prasarana jamban yang digunakan sehari-hari sudah tersedia.

Hasil penelitian ini sejalan dengan penelitian Umiati (2010) menunjukkan adanya hubungan antara kepemilikan jamban keluarga dengan kejadian penyakit berbasis lingkungan (diare) di wilayah kerja Puskesmas Nogosari Kabupaten Boyolali Tahun 2009 dimana nilai signifikan $p=0,018$. Dengan belum memiliki jamban sendiri,dapat menyebabkan timbulnya kejadian diare pada balita responden yang dikarenakan kotoran tinja yang tidak terkubur rapat akan mengundang lalat maupun tikus yang akan berdampak terhadap kesehatan dan lingkungan.

Penelitian lain yaitu Rahadi (2005) yang menyimpulkan bahwa ada hubungan antara kepemilikan jamban dengan kejadian penyakit berbasis lingkungan (diare) di Desa Panganjaran Kabupaten Kudus yaitu sebanyak $68,7 \%$ penduduk telah memiliki jamban. Kejadian penyakit berbasis lingkungan (diare) ini disebabkan karena sebanyak 22,1\% tinja manusia dibuang di kebun atau pekarangan rumah.

Ketersediaan serta kondisi jamban guna memutuskan mata rantai penularan penyakit saluran pencernaan melalui perantara vektor dengan tidak membuang air besar disembarang tempat, sedangkan kondisi prasarana jamban yang ditemukan pada saat observasi yang tidak terawat dari segi kebersihannya, mudah dijangkau oleh serangga atau vektor seperti lalat dan kecoa, 
Jurnal Sulolipu : Media Komunikasi Sivitas Akademika dan Masyarakat

Vol. 20 No.2 2020

e-issn : 2622-6960, p-issn : 0854-624X

menimbulkan bau serta lantainya yang tidak kedap air, dan konstruksi jamban yang tidak landai/miring ke arah lubang jamban.

Pada jamban yang konstruksinya landai/miring ke arah lubang jamban, tinja akan segera tergelontor ke dalam lubang sehingga memudahkan masuknya tinja langsung ke saluran pembuangan atau penampungan. Hal ini akan mencegah serangga atau tikus menjamah tinja, kemudian kebersihan jamban juga harus terpelihara atau tangki penampungan serta tempat duduk/jongkok juga harus bersih untuk mencegah datangnya vektor penyakit seperti lalat ataupun tikus sehingga diperlukan adanya alat-alat pembersih serta sarana air bersih yang cukup (Ismail, et al. 1986). Keberadaan jamban juga tidak boleh mencemari sumber air bersih warga, jaraknya dari sumber air bersih minimal 10 meter untuk mencegah tercemarnya air oleh bakteri melalui aliran air tanah (Meithyra, 2014).

c. Saluran Pembuangan Air Limbah Tabel 3

Hubungan Ketersediaan prasarana sanitasi SPAL terhadap penyakit berbasis lingkungan di Lingkungan Nipa dan Lingkungan Appasarenge Kelurahan Bentenge Kota Bulukumba Tahun 2020

\begin{tabular}{|c|c|c|c|c|}
\hline \multirow{2}{*}{$\begin{array}{c}\text { Ketersediaa } \\
\text { n Prasarana } \\
\text { Sanitasi } \\
\text { Pembuanga } \\
\text { n Sampah }\end{array}$} & \multicolumn{2}{|c|}{$\begin{array}{c}\text { Penyakit } \\
\text { Berbasis } \\
\text { Lingkungan }\end{array}$} & \multirow[t]{2}{*}{$\begin{array}{c}\text { Tota } \\
\text { I }\end{array}$} & \multirow[t]{2}{*}{$\begin{array}{c}\text { Persent } \\
\text { ase ( } \% \\
\text { ) }\end{array}$} \\
\hline & $\begin{array}{l}\text { Tidak } \\
\text { Terken } \\
\text { a PBL }\end{array}$ & $\begin{array}{l}\text { Terken } \\
\text { a PBL }\end{array}$ & & \\
\hline Tersedia & 192 & 8 & 200 & 97.5 \\
\hline $\begin{array}{c}\text { Tidak } \\
\text { Tersedia }\end{array}$ & 5 & 0 & 5 & 2.5 \\
\hline Total & 197 & 9 & 205 & 100 \\
\hline
\end{tabular}

Berdasarkan Crosstabulation untuk mengetahui hubungan ketersediaan prasarana saluran pembuangan air limbah (SPAL) terhadap penyakit berbasis lingkungan di Lingkungan Nipa dan Lingkungan Appasarenge Kelurahan Bentenge Kota Bulukumba diperoleh hasil dari 205 sampel yang diteliti, yang memiliki ketersediaan prasarana sanitasi saluran pembuangan air limbah serta tidak terkena penyakit berbasis lingkungan sebanyak 193 rumah $(96 \%)$ dan yang terkena penyakit berbasis lingkungan sebanyak 8 rumah $(4,0 \%)$.
Sedangkan yang tidak memiliki ketersediaan prasarana sanitasi saluran pembuangan air limbah serta tidak terkena penyakit berbasis lingkungan sebanyak 4 rumah (100\%) dan yang terkena penyakit berbasis lingkungan sebanyak 0 rumah $(0 \%)$.

Berdasarkan uji Chi-Square, maka didapatkan nilai signifikan $p$-value 1,000 karena nilai signifikan $1,000>(0.05)$ berarti hipotesis ditolak ( $p$-value $>\alpha$ ) uji statistik menunjukkan tidak ada pengaruh antara ketersediaan prasarana sanitasi saluran pembuangan air limbah (SPAL) dengan kejadian penyakit berbasis lingkungan. Berdasarkan hasil observasi dan wawancara terhadap responden di Lingkungan Nipa dan Lingkungan

Appasarenge Kelurahan Bentenge Kota Bulukumba saluran pembuangan air limbah (SPAL) dengan memanfaatkan drainase sebagai sarana, masih ada yang tersumbat, terdapat genangan, serta dipenuhi oleh sampah sehingga dapat menyebabkan vektor berkembang biak pada saluran pembuangan air limbah (SPAL) tersebut, dan juga dapat menyebabkan meluapnya air dari drainase pada musim hujan disebabkan karena tergenangnya air karena sampah-sampah yang ada dalam drainase.

Penelitian ini tidak sejalan dengan penelitian Anna (2015) bahwa terdapat hubungan antara kondisi dan ketersediaan saluran pembuangan air limbah (SPAL) dengan kejadian penyakit berbasis lingkungan (diare) dengan nilai $p=0,000<\alpha(0,05)$. Hasil penelitian ini sejalan dengan pendapat Notoatmodjo (2011), bahwa air limbah yang tidak diolah terlebih dahulu akan menyebabkan berbagai gangguan kesehatan masyarakat dan lingkungan hidup antara lain menjadi transmisi atau media penyebaran penyakit, menjadi media berkembangbiaknya mikroorganisme patogen, menjadi tempat hidup larva nyamuk, menimbulkan bau yang tidak sedap, dan menjadi sumber pencemaran air permukaan, tanah dan lingkungan hidup lainnya serta menyebabkan kejadian penyakit berbasis lingkungan seperti penyakit diare, demam thypoid dan lain sebagainya.

Saluran pembuangan air limbah (SPAL) dimaksudkan agar tidak ada air yang tergenang di sekitar rumah, sehingga tidak menjadi tempat perindukan serangga atau dapat mencemari lingkungan maupun sumber air. Air limbah domestik termasuk air bekas mandi, bekas cuci 
Jurnal Sulolipu : Media Komunikasi Sivitas Akademika dan Masyarakat

Vol. 20 No.2 2020

e-issn : 2622-6960, p-issn : 0854-624X

pakaian, maupun perabot dan bahan makanan dan lain-lain. Air ini mengandung banyak sabun atau detergen dan mikroorganisme. Selain itu, ada juga air limbah yang mengandung urine manusia. Upaya yang dapat dilakukan dalam mencegah penularan penyakit berbasis lingkungan adalah sebaiknya dengan membuat saluran pembuangan air limbah yang tertutup dan selalu menjaga sanitasi saluran pembuangan air limbah agar tidak ada genangan dan menjadi media penularan penyakit (Langit, 2016).

\section{d. Pembuangan Sampah}

\section{Tabel 4}

Hubungan Ketersediaan prasarana Sanitasi

Pembuangan Sampah Terhadap Penyakit

Berbasis Lingkungan di Lingkungan Nipa dan Lingkungan Appasarenge Kelurahan

Bentenge Kota Bulukumba Tahun 2020

\begin{tabular}{|c|c|c|c|c|}
\hline \multirow{2}{*}{$\begin{array}{l}\text { Ketersedia } \\
\text { an } \\
\text { Prasarana } \\
\text { Sanitasi } \\
\text { Pembuang } \\
\text { an } \\
\text { Sampah }\end{array}$} & \multicolumn{2}{|c|}{$\begin{array}{c}\text { Penyakit Berbasis } \\
\text { Lingkungan }\end{array}$} & \multirow[b]{2}{*}{ Total } & \multirow[b]{2}{*}{$\begin{array}{l}\text { Persenta } \\
\text { se }(\%)\end{array}$} \\
\hline & $\begin{array}{l}\text { Tidak } \\
\text { Terken } \\
\text { a PBL }\end{array}$ & $\begin{array}{l}\text { Terken } \\
\text { a PBL }\end{array}$ & & \\
\hline Tersedia & 192 & 8 & 200 & 97.5 \\
\hline $\begin{array}{c}\text { Tidak } \\
\text { Tersedia }\end{array}$ & 5 & 0 & 5 & 2.5 \\
\hline Total & 197 & 9 & 205 & 100 \\
\hline
\end{tabular}

Berdasarkan Crosstabulation untuk mengetahui hubungan ketersediaan prasarana sanitasi pembuangan sampah terhadap penyakit berbasis lingkungan di Lingkungan Nipa dan Lingkungan Appasarenge Kelurahan Bentenge Kota Bulukumba diperoleh hasil dari 205 sampel yang diteliti, yang memiliki ketersediaan prasarana sanitasi pembuangan sampah serta tidak terkena penyakit berbasis lingkungan sebanyak 192 rumah (96\%) dan yang terkena penyakit berbasis lingkungan sebanyak 8 rumah (4.0\%). Sedangkan yang tidak memiliki ketersediaan prasarana sanitasi pembuangan sampah serta tidak terkena penyakit berbasis lingkungan sebanyak 5 rumah $(100 \%)$ dan yang terkena penyakit berbasis lingkungan sebanyak 0 rumah ( $0 \%)$.

Berdasarkan uji Chi-Square, maka didapatkan nilai signifikan $p$-value 1,000 karena nilai signifikan $1.000>(0.05)$ berarti hipotesis ditolak ( $p$-value $>\alpha$ ) uji statistik menunjukkan tidak ada pengaruh antara ketersediaan prasarana sanitasi pembuangan sampah dengan kejadian penyakit berbasis lingkungan. Berdasarkan hasil observasi dan wawancara terhadap responden di Lingkungan Nipa dan Lingkungan Appasarenge Kelurahan Bentenge Kota Bulukumba penampungan sampah yang tersedia memiliki wadah yang kondisinya tidak kedap air, tidak tertutup sehingga sangat mudah untuk dimasuki oleh serangga dan vektor penyakit.

Hasil penelitian ini sejalan dengan hasil penelitian yang dilakukan oleh Muh.Saleh (2014) yang menemukan bahwa tidak ada hubungan antara tempat sampah dengan kejadian penyakit berbasis lingkungan (diare) dengan nilai siginifikan $p=0,947>\alpha(0,05)$ di wilayah kerja Puskesmas Baranti Kabupaten Sidrap Tahun 2013.

Pembuangan sampah di lingkungan Nipa dan lingkungan Appasarenge didominasi menggunakan kontainer (TPS) yang kondisinya tidak memenuhi syarat. Kondisi wadah/tempat pembuangan sampah yang ditemukan terbuka, tidak kedap air, menimbulkan bau serta menjadi tempat untuk berkembangbiak binatangbinatang seperti lalat, kecoa dan lainnya.

Sampah merupakan salah satu penyebab tidak seimbangnya lingkungan hidup. Bila dibuang dengan cara ditumpuk saja akan menimbulkan bau dan gas yang berbahaya bagi kesehatan manusia. Selain itu tradisi membuang sampah disungai dapat mengakibatkan pendangkalan yang demikian cepat, banjir, juga mencemari sumber air permukaan karena pembusukan sampah tersebut. Pengaruh sampah secara biologis khususnya sampah organik yang mudah membusuk merupakan media mikroorganisme untuk hidupnya, proses ini akan menimbulkan terbentuknya bau yang menarik beberapa vektor penyakit dan binatang pengganggu (Langit, 2016).

Dampak terhadap kesehatan pembuangan sampah yang tidak terkontrol dengan baik merupakan tempat yang sangat cocok bagi beberapa organisme dan menarik berbagai binatang seperti lalat yang dapat menimbulkan penyakit. Potensi bahaya yang ditimbulkan adalah penyakit diare, cholera, tifus, menyebar dengan cepat di tempat yang pengelolaan sampahnya kurang memadai. Tempat sampah harus memenuhi syarat-syarat kesehatan dengan tujuan agar tempat sampah 
Jurnal Sulolipu : Media Komunikasi Sivitas Akademika dan Masyarakat

Vol. 20 No.2 2020

e-issn : 2622-6960, p-issn : 0854-624X

tidak menjadi sarang atau tempat berkembangbiaknya serangga ataupun vektor penyakit. Upaya yang dapat dilakukan masyarakat agar dalam pembuangan sampah tidak menjadi sarang vektor penyakit adalah dengan menyediakan dan menutup tempat sampah rapat-rapat (Langit, 2016).

\section{Kesimpulan dan Saran}

1. Kesimpulan

Berdasarkan hasil penelitian yang dilakukan di Lingkungan Nipa dan Lingkungan Appasarenge Kelurahan Bentenge Kota Bulukumba Tahun 2020, maka dapat disimpulkan sebagai berikut:

a. Ketersediaan prasarana penyediaan air bersih memiliki hubungan yang signifikan terhadap penyakit berbasis lingkungan.

b. Ketersediaan prasarana prasarana jamban keluarga memiliki hubungan yang signifikan terhadap penyakit berbasis lingkungan.

c. Ketersediaan prasarana saluran pembuangan air limbah tidak memiliki hubungan yang signifikan terhadap penyakit berbasis lingkungan.

d. Ketersediaan prasarana pembuangan sampah tidak memiliki hubungan yang

\section{DAFTAR PUSTAKA}

Anna D, P., Dina, D, N., \& Lolita, S. 2015. Hubungan Kondisi Saluran Pembuangan Air Limbah, Sarana Air Bersih dan Jamban Dengan Kejadian Diare Pada Balita Di Wilayah Kerja Puskesmas Simpang Agung Kecamatan Seputih Agung Lampung Tengah. Jurnal Dunia Kesmas Volume 4.Nomor 3. Juli 2015, 157-162.

Dinas Kesehatan Kabupaten Bulukumba. 2015. Jumlah Kasus Kejadian Penyakit Diare. Bulukumba..

Kementerian Kesehatan 2010. Peraturan Menteri Kesehatan Republik Indonesia No. 492/Menkes/Per/2010. Peraturan Menteri Kesehatan Republik Indonesia. P. Menkes

Kementerian Kesehatan 2016. Profil Kesehatan Dasar Tahun 2015. Jakarta

Langit. L. S. 2016. Hubungan Kondisi Sanitasi Dasar Rumah dengan Kejadian Diare Pada Balita Di Wilayah Kerja Puskesmas Rembang 2. Jurnal Kesehatan Masyarakat. 4(April). Pp.160-165.

Meithyra, M., Surya, D., Evi, N. 2014. Hubungan Sanitasi Jamban dan Air Bersih Dengan Kejadian Diare Pada Balita Di Kelurahan Terjun Kecamatan Medan Marelan Kota Medan. Fakultas Kesehatan Masyarakat Universitas Sumatera Utara. Sumatera

Muh. Saleh \& Rachim, L. H. 2014. Hubungan Kondisi Sanitasi Lingkungan dengan Kejadian Diare pada Anak Balita di Wilayah Kerja Puskesmas Baranti Kabupaten Sidrap. Jurnal Kesehatan, VII(1), 221-233.

Notoatmodjo. S. 2010. Metodelogi Penelitian Kesehatan. Jakarta: Rineka Cipta

Notoatmodjo. S. 2011. Kesehatan Masyarakat: Ilmu Dan Seni. Jakarta: Rineka Cipta.

Prayitno. B. 2016. Skema Inovatif Penanganan Permukiman Kumuh. Cetakan Kedua. 13-15. Yogyakarta: Gadjah Mada University Press.

Profil Kesehatan Provinsi Sulawesi Selatan. 2019. Jakarta.

Pusat Data dan Informasi (PUSDATIN). 2019. Data dan Informasi Profil Kesehatan Indonesia. Jakarta. 
Jurnal Sulolipu : Media Komunikasi Sivitas Akademika dan Masyarakat

Vol. 20 No.2 2020

e-issn : 2622-6960, p-issn : 0854-624X

Peraturan Pemerintah. 2016. Penyelenggaraan Perumahan dan Kawasan Permukiman. Jakarta: Peraturan Pemerintah.

Republik Indonesia. Undang-undang Nomor 01 Tahun 2011 Tentang Perumahan dan Kawasan Permukiman. Jakarta.

Republik Indonesia. Peraturan Menteri Pekerjaan Umum dan Perumahan Rakyat Nomor 27 Tahun 2016 Tentang Penyelenggaraan Sistem Penyediaan Air Minum. Jakarta.

Republik Indonesia. Peraturan Menteri Kesehatan Republik Indonesia Nomor 03 Tahun 2014 Tentang Sanitasi Total Berbasis Masyarakat. Jakarta.

Umiati. 2010. Hubungan Antara Sanitasi Lingkungan Dengan Kejadian Diare Pada Balita Di Wilayah Kerja Puskesmas Nogosari Kabupaten Boyolali Tahun 2009. SKRIPSI. Surakarta: Fakultas Ilmu Kesehatan Masyarakat Universitas Muhammadiyah Surakarta. 